\title{
Exploration of Industrialization Road of Folk Dance Fanshanjiaozi
}

\author{
Zaidong Wang \\ School of Music and Performing Arts, Sichuan University of Arts and Science, Dazhou 635000, \\ China
}

\begin{abstract}
The folk dance Fanshanjiaozi in the eastern region of Sichuan is in the plight at present, it is necessary to emancipate the minds, build fine products, make good use of Internet functions, follow the marketization laws, develop music bases, work industrialization road, and then better inherit and develop Fanshanjiaozi.
\end{abstract}

Keywords: folk dance; Fanshanjiaozi; industrialization.

\section{Introduction}

Longgang Town is located in the southwest of Pingchang County, Bazhong City, Sichuan Province. Here green hills and blue waters, cultivation in the morning and weeding in the evening, It is a quiet and peaceful southern town. In the past years, every time the festival, or when the wedding, some villagers spontaneously organize themselves, dressed in red and green, pick up a pair of small cymbals and wave them in their hands, many times there will be a small gong and drum band that play the suona alongside, if the conditions are not enough, as long as one person can also perform. The shape of this small cymbals is very similar to the dumplings that are eaten during the festival, and during the performance, both hands need to swing the rope, turn the pair of the old festival, and over the top of the head, or turn around and flip around the waist and legs, therefore, this folk dance was initially called " Fanshengjiaozi." Because Longgang Town is located in the Daba Mountain Area, it is often necessary for performers to tramp over mountains and through ravines to pick up bride, therefore, it is also called "Fanshanjiaozi".

The main props of Fanshanjiaozi: the original name of the dumpling is cymbals, the folks call it as small cymbals, Chinese and foreign bands all use, it originated from West Asia, entered the Central China during the Northern Wei Dynasty, and it is often used in the percussion music part of the band with big cymbals for accompaniment. Before and after the Song Dynasty, the Nuo Opera (it is also called as the Duangong Opera) evolved from the official ritual ceremony to the folk witchcraft (exorcism) and sacrifice (honor the God) activities, during this period, the action of accompaniment musical instruments cymbals from both hands beat to gradually became some relatively complicated up and down vaudeville actions, makes this simple accompaniment instrument from behind the scenes to the stage, and becomes one of the main props of the event.

According to the information of the cultural center of Pingchang County [1], during the Xianfeng era of the Qing Dynasty, the wizard Su Xintai and his junior fellow apprentice Li Mingliang of Longgang Town improved beat of cymbals in the witchcraft activities, lengthened the rope of the cymbals, stretched or lengthened the rope while waving, carried out various collision and beat actions around the body. Later, from generation to generation, various accompaniment music and singing were added, and the performers showed a beautiful figure and shape, which seemed livelier and more festive. Fanshanjiaozi thus folk dance has gradually become the traditional repertoire of Longgang Town, and has developed to Yingshan County and Daxian County and so on. In 1983, the national "Top ten Major Literature and Art Collection" rescue project, the cultural center of Pingchang County collected and sorted out the "Fanshanjiaozi" into "Dance Collection of Pingchang County Volume" and "Dance Integration Daxian District Volume" and included it in "Sichuan Province Volume", "National Volume", with the protection project of intangible cultural heritage, in March 2009, the Fanshanjiaozi was selected to the second national intangible cultural heritage, in August 2011, was selected as the first intangible cultural heritage list of Sichuan Province, in 2010, Longgang Town officially established the "Fanshanjiaozi folk art group of Pingchang County", the county-level inheritor Wang Tianguo took the head, during this period, the Fanshanjiaozi were well developed. 
However, with the development of the economy, the young people of the art ensemble go out to work in succession, leave a few old members, and the activities of the art ensemble shrink gradually. In 2016, even Wang Tianguo, the head of the group, left Longgang Town, left the jiaozi art he loved for a lifetime, he went to work in Chengdu. In the telephone contact, the head Wang explained: "there are two main reasons: young and middle-aged are out, namely no one plays, no one sees, secondly, the provincial non-genetic learning base and Longgang Town submitted for Chinese traditional village, these two applications in the village have not been approved, and there is no government support. "No one, no money, this is the dilemma faced by most of China's intangible cultural heritage, including the Fanshanjiaozi." The great environment for economic development, the appreciation angle of people's art and the changes of hobbies, and the rapid update of the media, these are factors that lead to the decline of domestic traditional local music day by day.

Faced with this situation, the country has issued a series of documents and policies, hope to improve the current plight of local traditional music through these measures. At the 2014 literary work symposium, General Secretary Xi pointed out at the 2014 literary and artistic symposium, literary works with deep thinking, artistic skills; well-produced is the horn of advance of the times, tell the Chinese story well, spread the Chinese voice well, elucidate the Chinese spirit, show the Chinese style and features, and realize the creative transformation and innovative development of Chinese culture. Later, the National Radio and Television Administration issued the "Several Opinions on Promoting the Development of China's Music Industry", also proposed to promote the publication of excellent domestic original music works, implement music talent training program and promote the construction of national music industry base, various provincial governments across the country have also issued 13th Five-Year Plan Documents for the province's music industrialization, the general idea is to promote the development of new cultural formats, to form an industrial systems which cover creative design, animation games, publication, film and television, music and other modern industries; to build high-end industrial clusters with cultural tourism, entertainment, animation game and creative design as the core. This series of policy-level measures have given everyone a clear signal and direction, namely developing local traditional music, it is necessary to work the industrialization road, effectively integrating art and economy, which is fundamental road to achieve sustainable development. Therefore, Fanshanjiaozi of Longgang Town must be inherited, innovated and developed; we should take the important speech of General Secretary Xi as the guiding ideology, take the several opinions of the National Radio and Television Administration as the basic principle, development plan issued by the government as the action plan is used to solve the plight, specifically, there are the following aspects.

\section{Create High-quality Culture}

1. Deep thoughts: as a traditional folk culture more than 150 years of history, it has excellent side and must have a side that is not suitable for the socialist core values. At present, Longgang Town in the program aspect, it focuses on the festival, weddings and funerals, which people need to create and perform. Among them, festival and weddings and funerals are mainly festive movements and music, most of them are popular with the masses, but there are also very few contents that need to be changed, for example, during the festive performances, in the process of paying a New Year call from house to house, there are action and lyrics which ask for money to host and audiences, if the number of rewards is not satisfactory, the performers will sing bad lyrics or dance bad behaviors; when marrying, there will occasionally be unreasonable, temporary forcing up commodity price, and sometimes even the wedding palanquin will be left in the middle of the mountain; when praying for the patients, some performers in order to increase the income, and casually add some eating the stove ash and drinking black dog blood in old society, etc., these feudal superstitious behaviors intensify the condition; these improper conducts blacken the traditional art that is gradually declining, hurt the people' feelings on the Fanshanjiaozi, lose the trust and love on traditional art, and corrupt the spiritual beliefs of the masses. 
Therefore, through the census of art materials, the inheritors at all levels are encouraged to collect traditional drama, rearrange and adapt, get rid of vulgar, degraded, kitsch, stale works and some acts, and formulate new industry norms, from ideological and works, rectify and reform from the ideology, works, and performance behaviors, abandon the disadvantages and take in the advantages, carry forward ancient folk art and reproduce the world. At the same time, the relevant government departments issued policies, encourage local drama writers and songwriters to go to the public, and combine the needs of the times, create excellent works that are suitable for the mainstream thinking of modern Chinese society, conform to the socialist core values, embody the spirit of Chinese dreams, and promote Chinese traditional culture, and truly create new Fanshanjiaozi with deep thought, and stand the test of society and time.

2. Exquisite art: According to the difference in performance skills, Wang Huchuan once thought that the Fanshanjiaozi were divided into four major schools: Guo, Tan, Wu, Yue [2], but in the interview, Wang Tianguo thought that there is no need to divide detailed, from the drama content, Fanshanjiaozi can be divided into two major schools, Guo school(original school) and Tan school (school), for example: Guo school's masterpiece, overlapping the large table of farmer's meal (3, 5, 7), The pagoda is set up as a Taoist altar (temple of heaven), "temple of heaven Yueshen" is famous for "shock, danger, and oddness"; Guo school's inheritor, Guo Dengjun's self-composed, self-created, self-acted original ecological program, "Water Shadow" is popular with the masses due to "mildness, fun"; Tan school's innovative works, the Northeast "donkey" is introduced as props, " overjoy" is $\mathrm{v}$ to marriage; also gathered the Guo school's "mildness, odd", Tan school's "new, strong", Deng Shengxue's work "platform", which is famous for its difficult actions and so on.

These works are historically saved classic programs or created by artists; they truly represent the artistic characteristics of the Fanshanjiaozi and the cultural connotations of Chuandong, and they are deeply loved and praised highly by the masses. However, today's stage arts are increasingly refined; in order to be accepted by more audiences, especially young people, and achieve sustainable development, Fanshanjiaozi must be reformed from the perspective of exquisite art. This requires art workers to study these works in depth, and organize artistic elements such as pace, gestures, posture, action, melody of the music used, beats and rhythm, instruments used, etc., establish a documentary archive, both old and new artists can on this basis, while retain the essence of the most original music works, blend modern music elements, bring forth the new through the old, integrate the advantages of each genre, develop a new artistic composition that is more suitable for modern young people to appreciate walking, stage actions, and melody rhythm.

Taking the stage action as an example; the art core of Fanshanjiaozi is to wave the jiaozi, the action has some vaudeville nature, especially the innovative platform jiaozi, the action is difficult, novel and very ornamental, the artistic standards of the international acrobatics stage have been reached. Therefore, in the commercial performance of Fanshanjiaozi, it is possible to learn from the current international popular acrobatics, such as Ukrainian aerial silk dance, German funny dog training, Russian high-altitude swing, Colombian rotating wheel performance, British microphone performance Doni Mo and other programs, since these programs can be toured around the world and are welcomed, their stage design, costume props, lighting sound and other commercial elements are worthy of thought and reference for Fanshanjiaozi.

3. Exquisite production: art needs to cater to the needs of the times; blindly hold the original ecology, original flavor, it is not appropriate in the information age. At present, the final consumers of music industry, young people aged 18-25 account for the mainstream. The clothing of Fanshanjiaozi is mainly composed of bright colors such as red, yellow and green, the actors are simple in style, traditional folk music takes suona as the main accompaniment music, these elements are too different from the aesthetics of the current young people, it is difficult for young people to accept. Therefore, with reference to the most popular art product components, it is necessary to carry out reforms on the basis of retaining the essence and characteristics of Fanshanjiaozi.

The music art market covers music stage performances, CD record, MV (music videotape) albums, MTV (music TV), anime music, game music, TV and movie soundtracks, etc., these are the path of 
commercialization and marketization of music. Among them, the animated peripheral products that are very popular among young people are the most convincing.

On July 28, 2017, the Hong Kong Music and Animation Base held a three-day 4th Hong Kong Music and Animation Festival at the Hong Kong Convention and Exhibition Center; singers performed anime music in the convention and exhibition famous, peripheral products of animation program were the main selling points and strongly chased after by young people. Hundreds of thousands of young people rush into the pavilion, and they all bought their favorite anime peripheral products, a fist-sized doll was priced at 25,000 Hong Kong dollars, and the buyers go to and fro in constant streams. Although the organizers did not disclose the specific data, but only look at the hot scene of the scene sales, it is not difficult to imagine the income of the three-day exhibition, it is an astronomical number.

\section{Spread National Voice}

The development of any peripheral product can't do without the promotion of its background art, make most people know, understand, and love, and finally can stimulate their desire to buy products. The wine is also afraid of the deep alleys, therefore, propaganda of national art, and spread of national voice are important means to develop traditional art and let more people understand and love folk dances in a remote mountainous area.

In addition to governmental support, negotiate with enterprise and venture capital institutions through various channels, and cooperate to create a music production company or music professional performance platform, on the basis of striving for a win-win situation, try our best to obtain all the funds that can be won, and based on this, gradually gain recognition and support from media at all levels, and promote in traditional media such as newspapers, radio stations, televisions, and use major online media to form official website, official Weibo, WeChat public account, WeChat APP, etc., spread local, folk, and national voices to the whole society, thoroughly spread the image of "Fanshanjiaozi" all over the country, make the whole world see, hear and understand the national folk distinctive music culture from the mountainous areas of southwest China.

The national voice certainly contains language; language is also an important factor to restrict cultural development, if you want to go out, you must adapt to the language characteristics of different regions. The drama "Lin Huiyin" created by the Shanghai Pingju Group includes dialects, English and Mandarin in the lyrics; they all fit identity and cultural background of the characters and are highly praised after the performance. In contrast, the language part of the Fanshanjiaozi is not a big part, but the development of different language versions is also a factor that cannot be ignored, Mandarin, Cantonese, English version, etc., where to go, where to say, it is an important means to better integrate into local culture and win the love of local people.

\section{Industrial Promotion and Development}

To truly save a local music culture that is on the verge of extinction, it is not enough to study music alone, it should stand in market, and take it as a commodity, promoted and sold out, namely industrialization of "Fanshanjiaozi", let more people know, understand, love, buy it, and gradually cultivate a mature, standardized trading market, then fundamentally solve this problem. There are several phased conception and conception in industrial promotion and development aspects:

1. Industry promotion and development must first have funds, this aspect except to seek government support, it is more important to open up ideas and find ways to make money. Longgang Town has picturesque scenery, among which the former residence of Liu Bojian Martyr has always been the main tourist attraction of red tourism, and it has a very important position in the national red tourist attractions. In combination with the red tourism resources, unite tourism companies to develop musical and cultural tourism, and based on the current old members, based on the original traditional dramas, develop tourism programs with local characteristics, for example, using the form of Fanshanjiaozi to promote the glorious deeds of the revolutionary martyrs Liu Bojian, the form of 
welcoming the bride, sending bride and fetching bride are used to carry out fixed traditional wedding ceremony performance to show and propagate traditional art to tourists, activate Fanshanjiaozi performance economy, moreover, brand the cultural heritage of Longgang Town in the hearts of tourists, let more outsiders know and understand the Fanshanjiaozi, experience the unique local music charm of the Chuandong area and form a win-win model with the tourism companies.

Longgang Town not only has the former residence of martyrs, but also has a profound cultural background, unique natural landscape and beautiful ecological environment; Fairy Stone, Red Army Cave, Xiaozhaizi and Dadiping are well known. The Boyu Temple, the Kunniu Mountain, and Guanyinyan are beautiful and have unlimited scenery, and it has great value for protection and development. In combination with these tourist attractions, organize personnel to dig deep into resources, continue to declare "Chinese traditional villages" and "provincial non-genetic learning bases", and strive to win these two projects in the shortest time, and increase persuasiveness and playability for the development of tourism economy.

In addition to these regular patterns, when the Shanghai Pingju Group created "Lin Huiyin", first advocated the concept of "crowd funding" and obtained the first fund through crowd funding, this provides unlimited new ideas for more small businesses such as the Longgang Fanshanjiaozi art ensemble to earn initial capital on project.

2. Cultural inheritance is the inheritance of human beings, high-level creation and performance personnel are the objects and foundations of inheritance. After had certain influence and funds, we can start to recall the young members who go out to work, moreover, train some young people in the way of apprentices, and can also take the way which old artists go into the campus, unite with local colleges and universities, and introduce Fanshanjiaozi into classroom, organize teachers to create the Fanshanjiaozi performance course, set up the special class of the Fanshanjiaozi, and sign the graduate employment contract to carry out the human resources training of the inheritors, especially the Pingchang students, so while the inheritance has the successor, which greatly improve the overall performance level, in order to create a education highland in east Sichuan with local characteristics, inject fresh blood, and improve the professional quality and cultivation of college music teachers.

3. Create an industrial base: with basic human resources, financial resources, and influence, the original Fanshanjiaozi art ensemble will be used asordinary members of an organization to set up music production companies, create the Longgang Town Fanshanjiaozi industry base, and unite performance and record company, literary and artistic creation team, online music platform and other institutions work to create a music industry chain: the songwriters create good works, the performers and the bands complete the performances, the record companies release the audio and video of the works, and finally the music platform propagate, promote, use the influence brought by the platform propaganda, conduct tour exhibitions around the country, and finally form a complete music industry chain.

4. In the construction and management of the music industry base, refer to domestic and foreign music bases, and mainly promote the construction of four aspects:

(1) Construction of the industrial system: set up a basic performance group of Fanshanjiaozi, find a suitable performance brokerage company, get more commercial performances, music day performances, tour performances, etc.; rent or self-create network platform: digital music, live platforms, ticket platforms, etc., achieve music creation, making-up, promotion, sales cooperation; and get direct attention from investors or venture capital companies, and attract more fund sources.

In performance aspect, the domestic music days that are increasingly popular and perfect in are worth learning. Taking 2016 as an example, there are 202 performances throughout the year, and the comprehensive music days are the main, on the basis of more diversification, the vertical (specialized) music day is developing rapidly, such as the electronic zoo music day and the national anime music day, folk music day, etc. At the beginning of Fanshanjiaozi, it can be combined with other similar traditional art to make an intangible cultural (vertical) music day project, with the foundation, a Fanshanjiaozi special music day is not a dream.

Open music creation, record, publish, distribution, copyright trading, performance, education training, music derivative products, etc., connect the horizontal industrial chain of music, tourism, 
broadcast, film and television, network, hardware broadcasting equipment, musical instrument production, etc., basically form a comprehensive music industry system that responds to each other in the upstream and downstream and support every link.

(2) Digital communication system construction: the industrial base comprehensively cooperate with communication operators and network operators to expand the Internet, wireless communication network, cable TV network, and other digital communication channels, and develop mobile phones, mobile multimedia terminals, mobile hard disks, databases as carrier, etc., various music publishing forms use mobile hard disk and database as carriers and presentation form, the acquisition of digital music is more convenient, spread more widely, and the payment is more standardized under internet conditions.

(3) Construction of talent training system: in addition to the above-mentioned union with local colleges for the creation and training of performance inheritors, the base should also pay attention to the recruitment and self-cultivation of the overall music talents: music broker, producers, sound engineers, mixers, videographers, etc., they are all musicians, the combination of the stage is the whole system in the music occupation.

(4) Brand construction: embody the cultural characteristics of Bashu, pay attention to the balance of production, study and research, start from protecting copyright, cultivate the consciousness and spirit of open sharing and win-win, and increase the source of music creation. In particular, paying attention to enhancing the value of copyright and the popularity of musicians, for some enterprises with higher credibility, they can more confidently use these copyrights to spread these works and jointly create these works. Those classic works in the past can be secondarily excavated and repackaged by modern means, and their value characteristics will be played again, and then integrate the current operating methods of the Internet, and then spread out. Especially for the young user post$90 \mathrm{~s}$ and post-00s, really attract their attention and to these excellent works.

The development of the Internet has brought crisis to traditional music culture, and brings opportunities as well. Fanshanjiaozi from the southwest mountainous area, need to seize the opportunity, relies on the welfare of the relevant national policies, boldly absorbs the excellent elements of modern music, reform from the idea, bravely goes out, has fine cultural products, smooth distribution channel, a set of industrial planning, Fanshanjiaozi can change the status and destiny, and make due contributions to the promotion of national culture, then achieve true "thoroughly change the backwardness ".

\section{Acknowledgements}

Fund Project: General Project of Southwest Music Research Center "Promotion and Development of Folk Dance Fanshanjiaozi in Pingchan County", project number (xnyy2017011).

\section{References}

[1]. Pingchang County Record[M], Sichuan Science and Technology Press, 1990-01.

[2]. Wang Huchuan. The Cultural Origin and Dance Characteristics of the Han Folk Dance "Fanshanjiaozi"[J], Journal of Southwest University, 2008-11.

[3]. Yan Cong. Research on the Influence of Minority Music Industrialization on the Development of Modern Music[J], Guizhou Ethnic Studies, 2014-01.

[4]. Liu Ying. Thought on the Development of Folk Music Industrialization in Hebei Province[J], Hebei Academic Journal, 2013-07. 